\title{
Conceptualizing Resource Orchestration - The Role of Service Platforms in Facilitating Service Systems
}

\author{
Andreas Zolnowski \\ University of Hamburg \\ andreas.zolnowski@uni-hamburg.de
}

\author{
Markus Warg \\ Wedel University of Applied Sciences \\ mwa@fh-wedel.de
}

\begin{abstract}
The digitization, as the profound digital transformation of business activities, processes, competencies, and models, leads in many companies to the implementation of digital service platforms as a nucleus for rapid development and the implementation of reusable digital innovations and solutions. Based on service platforms, companies strive to gain superior resource density that enables interaction with customers and partners in real-time and foster service innovation. This paper focusses on the role and purpose of service platforms in value creation and in particular, the management of resources. For this, a longitudinal single-case study method is conducted that comprises three embedded case studies as units of analysis. In this context, the meta-theoretical foundations of $S-D$ logic are reflected and, as a result, resource orchestration as a management capability of service platforms is introduced and discussed. Moreover, the role of service platforms in managing resources in the development of innovative service systems is examined.
\end{abstract}

\section{Introduction}

To master the digitization, as the profound digital transformation of business activities, processes, competencies, and models [1], many companies design and execute digital strategies. Within these strategies, digital service platforms play an essential role $[2,3]$. From a practice-oriented perspective, a service platform can be defined as a "set of business and technology capabilities that enable rapid development and implementation of [..] innovations" [2]. As conceptualized by Lusch and Nambisan [4] service innovations emphasize collaborative processes, the application of specialized competencies, increasing resource liquefaction and resource density, and resource integration [4]. Moreover, innovations in service systems focus increasingly on IT-enabled, customer-centered, relationship-focused, and knowledge-intensive [5] value propositions that emphasize cocreation and a broad transparency of value creation activities [4].

To foster innovations, digital technologies enable service platforms that facilitate service systems in many different ways. Among other things, they (1) enable the provider to inform customers about value cocreation processes, (2) improve collaboration processes, (3) facilitate new services, (4) enable resource liquefaction, and (5) integrate customers into value creation and delivery $[6,7]$. For example, based on digital technologies, nowadays, customers can access and share information instantly. The simple access results in an increased transparency of product and service offerings, which affects customer behavior by getting a better match for products and services with their preferences; $[8,9]$. From a provider's perspective, data about customer interactions and behavior are gathered and processed. All information is used within the service system to create and offer tailored value propositions. For this, platforms create strong network effects that leverage economy of scale and scope.

Value propositions of service systems are provided in the interaction between different actors. The resulting value is created by interacting and integrating resources that are applied in the course of a previously defined goal [10]. During their application in value creation processes, the potential benefits of a resource are transformed into an actual and customer specific benefit [11]. Thus, the integration of resources is a central concept that describes a value creation process [12].

The execution of this requires new IT infrastructure capabilities to handle resources and thus, gain competitive advantage and required business agility. Business agility grounds on the ability to mobilize and integrate resources [2]. Hence, new IT infrastructure capabilities require new IT artifacts and conceptualizations, for example, to achieve respective strategic agility through implementing new capabilities. Capabilities like resource liquefaction and integration are enabled by digital service platform [4] 
and help to create reusable resource configurations for innovative service systems as well as to implement a set of new strategic initiatives induced by digitization.

Based on service platforms, companies strive to gain superior resource density that enables interaction with customers and partners in real-time and foster service innovation. This paper focusses on the role and purpose of service platforms in value creation and in particular, the management of resources. For this, a longitudinal single-case study method is conducted that comprises three embedded case studies as units of analysis. In this context, the meta-theoretical foundations of S-D logic are reflected and, as a result, resource orchestration as a management capability of service platforms is introduced and discussed. Moreover, the role of service platforms and resource orchestration in the development of innovative service systems is examined.

The remainder of the paper is organized as follows. After the introduction, related work from service research is presented. Thereupon, an overview of our case study as service platform at a German insurance company with three embedded case-studies is given. This is followed by a discussion of the management of resources within service platforms. The paper ends with a conclusion and outlook.

\section{Related work}

To understand the role of service platforms in facilitating service systems, in the following, S-D logic as the foundation of service systems, service systems, and service platforms are introduced.

\subsection{Service-Dominant Logic}

Vargo and Lusch initiated 2004 a paradigm shift by explaining a new perspective for overcoming the traditional goods focused understanding and emphasizing value and value creation, with the socalled Service-Dominant (S-D) Logic.

Following S-D Logic reflects a thinking which is consequently customer value driven and always cocreative. S-D Logic does not differentiate between goods and services. Rather, S-D Logic focuses on the generated value of a service process in which goods are one of many different input factors [13].

Value arises in the process of cocreation of actors, including the beneficiary; this implies that value creation is interactional and a process $[13,14]$.

Moreover, the application of operant resources (knowledge, skills) is the basis for all exchange between the actors. In the process of value creation, all actors are resource integrators. Considering resources, they can be differentiated in operand resources and operant resources. Operand resources are more static input factors like products, energy or components. Operant resources include dynamic, intangible factors like knowledge and skills which are the basis for the exchange of all resources. They are used in value creation, and they build the competitive advantage of a firm $[14,15]$.

Value is always uniquely and phenomenologically determined by the beneficiary. This means that value is individual, experiential, contextual and meaning laden $[13,14]$. Hence, considering the resulting value of service, value has a unique and subjective character. According to the value creation process, the emergence of value differentiates between value-in-use [15] and value-in-context $[16,17]$.

Value-in-use describes the value in the actual application of a service. Hence, a service unfolds its value only during its application in a particular environment. In contrast, value-in-context expands this perspective by the context of an actor. However, regardless of the factors which ultimately characterize the customer's value, it can be seen that a respective actor always assesses value in the service system [10, $13,15,18]$.

Based on the specific characteristics, service is defined as the application of operant resources (specialized competencies, skills, and knowledge), through deeds, processes, and performances for the benefit of another entity or the entity itself - selfservices [15]. Service in the sense of exercising operant resources is the basis of all exchange $[14,15]$. The distinguishing characteristics of service [15] are intangibility, heterogeneity (unlike goods, services cannot be standardized), inseparability (simultaneously produced and consumed), and perishability (service cannot be produced ahead). This leads to the effect that value for a beneficiary is created at the point of consumption - in a process - and not in the factory.

By using one's resources for the benefit of another, service reflects a process of interaction and cocreation. The resulting value is always cocreated by interacting and integrating resources that are applied in the course of a previously defined goal [10]. During their application in a value creation process, the potential benefits of resources are transformed into an actual and specific benefit [11].

\subsection{Service Systems}

S-D logic acts as a foundation on which a science of service systems and their value-cocreation interactions is built $[19,20]$. A service system is a configuration of resources, like people, technology, information that are connected to other systems by 
defined value propositions [21-24]. Hence, in service systems, different actors, and their resources are connected, to co-create mutual value [12]. Service systems are thus understood as open systems which can improve the state of another system or their state by acquiring external resources and sharing or applying existing resources [25].

Because resources and their application play a key role in value creation, their integration is one of the fundamental functions of a service system [11]. During their application in a value-adding process, potential benefits of a resource are transformed into an actual and specific benefit [11].

Another key role of the service system is to enable value cocreation; therefore so-called institutional components are helpful for the service systems [26].

\subsection{Service Platforms and the Service Dominant Architecture}

Value creation in service systems occurs in interaction with two or more different actors. Facilitating this interaction is the main reason for implementing a service platform. From a more theoretical point of view, Lusch and Nambisan [4] define a service platform as " $[. .$.$] a modular structure$ that comprises tangible and intangible components (resources) and facilitates the interaction of actors and resources (or resource bundles)." In practice, firms implement service platforms to enable rapid development and facilitate innovations [2].

Based on the literature on S-D logic and service systems, the Service-Dominant Architecture (SDA) was proposed [27]. It operationalizes concepts from service science in an architectural blueprint for the implementation of a service platform and thus, addresses and builds prerequisites for the development of new service. The SDA is aiming (1) to accelerate the capabilities in all customer-centric areas, (2) to achieve useful collaboration and cocreation, (3) to deepen the data-based customer understanding, and (4) to create networks of partners and other external service providers [28].

The architectural blueprint of the SDA enables the integration and orchestration of resources (such as processes, data, applications, functions) into agile, flexible and collaborative services in real-time. This facilitates the ability to use existing resources and thus, supports the implementation and development of service systems. To generate customer-centric solutions, the SDA implements the capabilities to capture (integration, participation), exchange (interaction), and orchestrate relevant resources. These capabilities allow to design and develop service systems of different granularity (micro, meso, and macro). To reach these goals, the SDA arranges and integrates the various resources, processes, and internal and external components needed for developing new solutions.

Based on the foundations of service systems [20, 25], SDA consists of three purposed technical service systems. Beside of the service systems, a data lake is introduced. The first purposed technical system is the System of Interaction (SOI). It creates interaction with the customer and thus enables cocreation. A customer can interact with the service provider via a variety of different interfaces. According to the interaction, the service provider can identify actual needs and requirements of the customer. Based on this knowledge, a company can implement customerspecific solutions. Since different resources are needed to realize solutions, the second purposed technical service system is the System of Participation (SOP). This system allows the integration of any partner into a fixed or loosely coupled system, in which resources for the development of new value propositions are orchestrated. Furthermore, existing resources of the company are provided in the third technical system, the System of Operant Resources (SOOR). Here, resources from the System of Records (SOR) are transformed into dynamically applicable information resources [29]. To enable the application of all information and resources in real-time, a supplementary data lake is established. It introduces new IT artifacts, related data structures, and management techniques as well as related data management capabilities such as big data approaches and techniques (like Hadoop, machine learning, artificial intelligence, algorithms) [27, 28].

As depicted in Figure 1, the SDA constitutes a combination of three systems, an environment for integrating external resources (such as customer actions), third party resources (such as GPS data, weather information), and internal resources (such as customer and contract information).

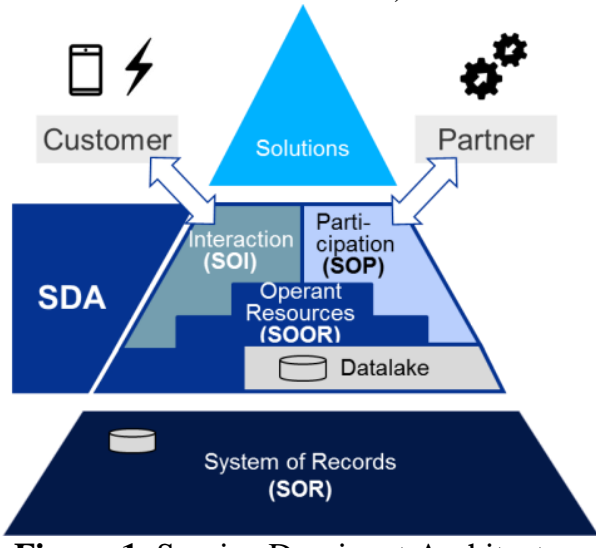

Figure 1. Service Dominant Architecture (based on [27, 28]) 


\section{Methodology and case study}

This research is based on a longitudinal single-case study method that comprises three case studies as units of analysis [30]. Hence, we investigate embedded case studies within a single case study on the implementation of the Service Dominant Architecture (SDA) in a German insurance company. Based on this method we can study contemporary phenomena in real life context, and thus to conduct exploratory research. Exploratory research can be applied in a context where theory seems to be inadequate or incomplete. Our single-case study considers multiple units of analysis [30]. These units comprise prototypically implemented use cases in the insurance company. Ultimately, this method allows gaining a holistic view [31] on the management of resources on a digital service platform.

In particular, our research gives insights on the digital transformation of a traditional insurance company in a highly competitive market. The products of the insurance company comprise from health care, accident, life and annuity insurance through property, personal liability and motor insurance down to credit and fidelity insurance schemes. Some short facts about the company: Revenues $>5$ billion Euro (2015), Employees >10.000 (2015), over 100 years in the insurance market. As we were able to accompany the insurance company over a longer period, we were able to gather information with deep insights about the entire transformation process. During this period, at least one researcher, attend all major workshops and steering groups. Furthermore, we have access to all documentations and employees that attend in this process. Our research started in October 2015, when the new strategy was formulated and adopted and includes all information until April 2017.

Due to the exploratory character of this study, we combined data from (1) internal documents, (2) workshops including the protocols, (3), discussions with employees from the management and (4) literature. As a starting point, we analyzed documents of the strategy. These documents allow us deep insights into the starting point in 2015, market situation, and strategic orientation of the IT until the end of 2017. Thereupon, we got information about all projects and prototypes in the IT organization. This comprises the reasoning, goals, timelines, and current status of each. Our information on the projects was updated quarterly. Furthermore, we were able to accompany most strategic workshops and to discuss the progress. Lastly, we were able to integrate literature on the SDA. All data were analyzed according to the objective, requirements, and purpose in developing and implementing the service platform as well as prototypical service systems.

In our case study, the company is implementing a digital strategy to react to changes in its environment, such as the changing customer behavior, new technologies, and new business models from digital attackers. To master these changes the insurance company is following a service-dominant strategy in its IT department. The major aim of this strategy is to establish a digital service platform with the target to create innovative value propositions and thus, gain competitive advantage. As the core of the digital strategy, the company decided to apply the Service Dominant Architecture (SDA) [27, 28].

In particular, we investigated the development and the implementation of three case studies. All three case studies are prototypically implemented on the SDA as a digital service platform. In each of our embedded case studies, the SDA was a mandatory basis for the implementation of the new service. In the following, the use cases are described in detail.

\subsection{Embedded case study 1 - invoice submission}

This use case implements a self-service portal for the submission of a medical bill (see Figure 2). Based

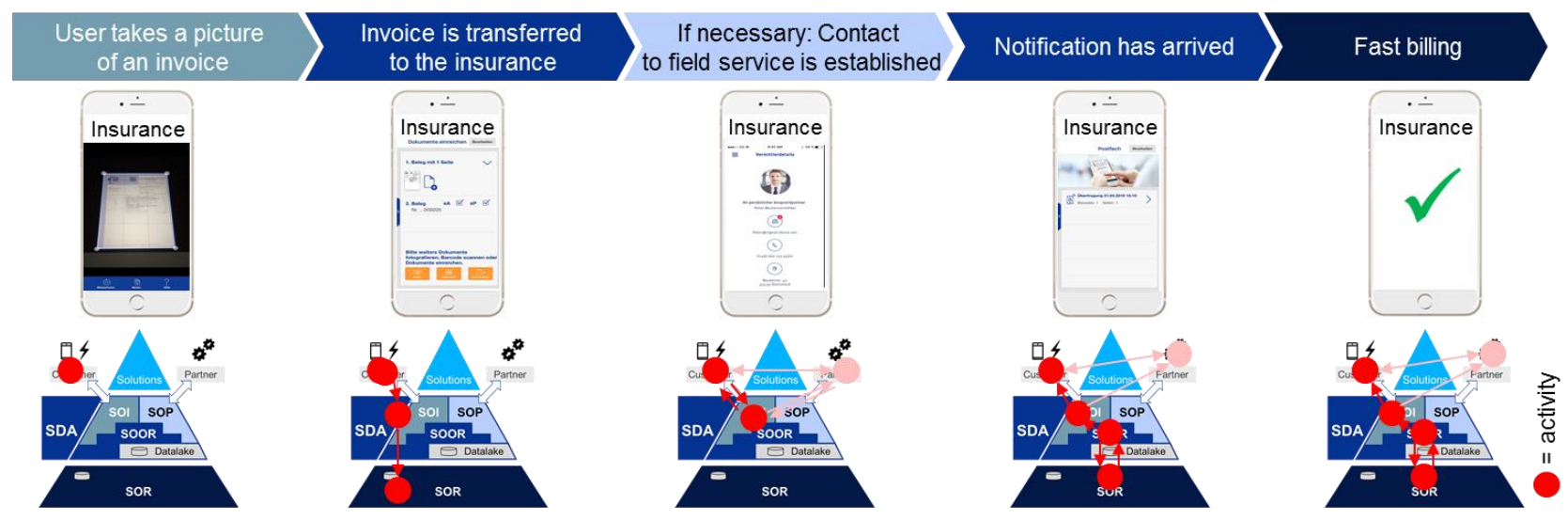

Figure 2. Embedded case study 1 - invoice submission 
on an existing offer, the application was redesigned and expanded. Within the extension, the field service has been added to the existing application.

As a prerequisite of this case, a customer has to visit a doctor and to get a bill for a physical examination. After this, the customer uses an App to submit the bill and to get a refund of his payment.

The use case starts with an activity of a user. He starts the mobile app and takes a photo of the medical bill. The photo is transferred through the SOI to the customer's insurance policy within the SOR. If the customer wants personal support, he can choose, if the photo is also transferred to the field service. In this case, the field service gets the photo and interacts directly with the customer. The fourth step comprises a notification for the arrival of the bill. As soon as the bill arrives in the SOR, the customer needs to get a notification. For this, a service in the SOOR transfers the bill to the SOR. After this, the SOOR service pushes through the SOI a notification to the customer. In case that the field service is supporting the customer, also the field service gets a notification. Depending on the amount of the bill, in the SOR, the insurance processes the photo and performs the refund of the customer's payment. The last step comprises a notification of the payment. For this, a service in the SOOR checks if the payment is already conducted within the SOR. If the payment is conducted, the SOOR service calls the SOI and pushes a notification to the mobile app of the customer. Analogously to the last step, if the field service is supporting the customer, he also receives a notification.

\subsection{Embedded case study 2 - check of insurance coverage}

The second case comprises a check of insurance coverage in a household insurance (see Figure 3). This application was a completely new offering to the customer. The design of the application started with a design thinking workshop and ended up in a prototypical implementation.
A prerequisite is that the user wants to check the insurance coverage for an object. Here, a birthday present. As in the other case, the customer uses a mobile app to take a photo of his birthday present and request an assessment of the value and its coverage.

The use case starts with an activity of the user. He starts the mobile app and takes a photo of his birthday present. He submits the photo via the SOI to the insurance. In the SOOR the system decides if an integration of an expert is necessary or not. If it is not necessary, the system redirects the photo via the SOP to an artificial intelligence system, which processes the photo. In the other case, the SOI redirects the request through the SOP directly to the expert. If the value of the birthday present seems to be higher, the photo is redirected via the SOP to an expert. This expert assesses the birthday present. After the assessment of the birthday present, the SOOR enters the value to the customer's insurance policy in the SOR. Simultaneously, the SOOR notifies the customer through the SOI about the results of the procedure.

In the case the insurance does not cover the birthday present, the insurance company must offer an expansion of the existing contract. In this case, a service in the SOOR interacts with the SOR and defines an individual offering for the customer. After this, the offering is transferred through the SOI to the customer.

\subsection{Embedded case study 3 - individualized information on website}

The third use case comprises individual information on the website of the insurance company (see Figure 4). Based on the actual opportunities of the service platform, the company implemented this function on the website.

In this case, the only prerequisite is that the visitor is an existing customer of the insurance company and has already visited the login area on the website. During his login, a cookie was written on his computer that helps to identify him at his next visit.

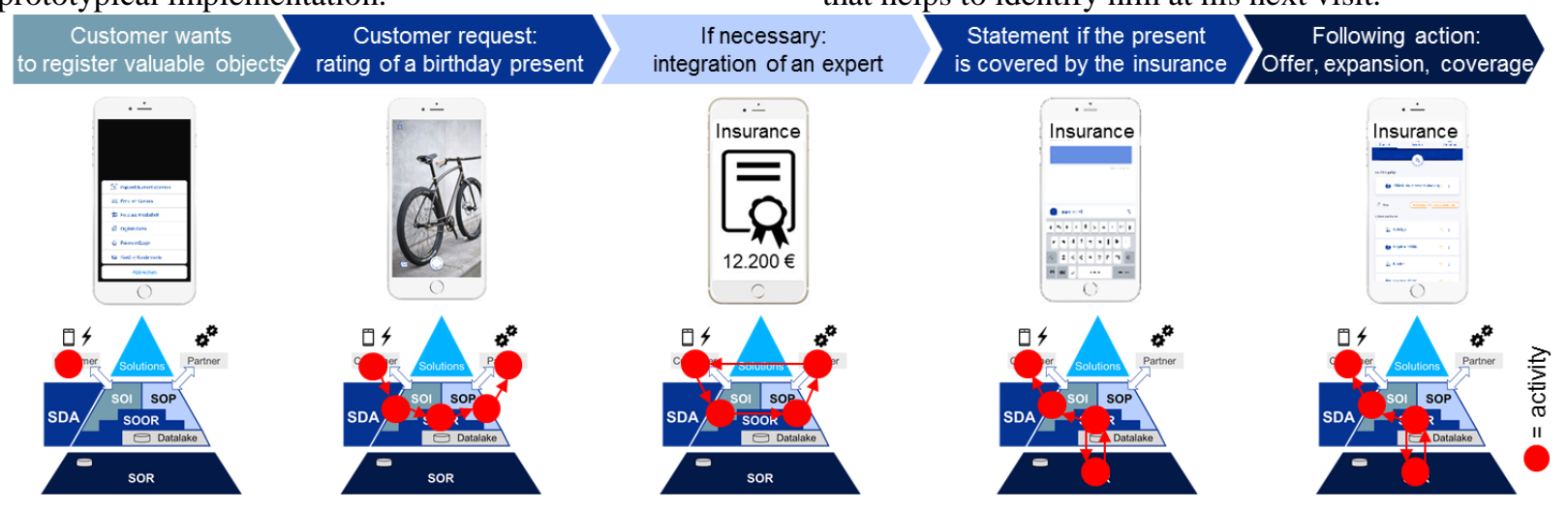

Figure 3. Embedded case study 2 - check of insurance coverage 
The use case starts with the identification and collection of necessary data. Within this step, the company searches for data that could be of interest to the customer. Once the company identifies meaningful data, the data is copied, if possible, to the SOOR. In this case, the SOOR loads crime statistics for Germany. This step is necessary to continue offering the individualization, even if the data source is not available. Analogously, specific customer data are transferred to the SOOR. This allows an identification of the customer in real time.

Now the customer has to enter the household insurance area on the website. At this moment the customer calls the SOI and submits his cookie with the identification to the SOOR. At this time, the system knows the identity of the customer. Based on this knowledge, the SOOR loads all necessary data about the customer. This comprises in particular information about the customer's contracts (Where does the customer live? Does he already have a household insurance?). At the same time, the SOOR loads the crime statistics from this cache. Thereupon, if complementary data are necessary, the SOOR can also load additional data through the SOP. Now, the SOOR can offer individualized information (crime statistics for his address) to the customer.

In the last step, the customer wants to contact the insurance company. At this moment, he contacts the SOOR through the SOI and gets redirected to either the direct service center or an external partner. The contact to the service center is established through the SOR. In contrast to this, the contact to the external partner is realized through the SOP.

\section{Discussion}

\subsection{Resource management on service platforms}

From a practice-oriented perspective, establishing a service platform is a crucial step in the implementation of a digital strategy [2]. By implementing the service platform, the insurer builds up the technical platform for an ecosystem that integrates resources of existing and new partners into a comprehensive platform. The platform is the basis for the development of a unified and reusable resource pool as well as of digital innovations.

Also from a service research perspective, service platforms play an important role in service innovation [4]. Based on the implementation of the SDA, this case study provides rich insights into the role of service platforms in managing resources. Resources are a fundamental concept in S-D logic. Considering the meta-theoretical foundations of S-D logic [4], actor-toactor networks, resource liquefaction, resource integration, and resource density, emphasize their importance [15]. Based on our case study, we reflect and discuss the operationalization of the metatheoretical foundations and thus, the role of service platforms in resource management (cf. Table 1).

Firstly, we consider actor-to-actor networks. The company's network was established by introducing the service platform with its technical service systems (SOI, SOP, and SOOR). Within this actor-to-actor network, different actors connect and integrate their resources to the service platform. All three case studies illustrate this characteristic by integrating customers and additional partners into the value creation. By doing this, the platform enables service exchange and cooperative value creation.

In our analysis, we identified two perspectives on the relationship between the actors. In particular, the ownership and visibility in value creation. Value creation processes on a corporate service platform are owned by the focal company and thus, by the owner of the platform. However, the origin of the integrated resources is not transparent to the user. Hence, the insurer carries out value creation under his brand.

Secondly, we analyzed how the service platform enables resource liquefaction. The case study shows in all cases the liquefaction of resources by consequently exploiting digital technologies. In all

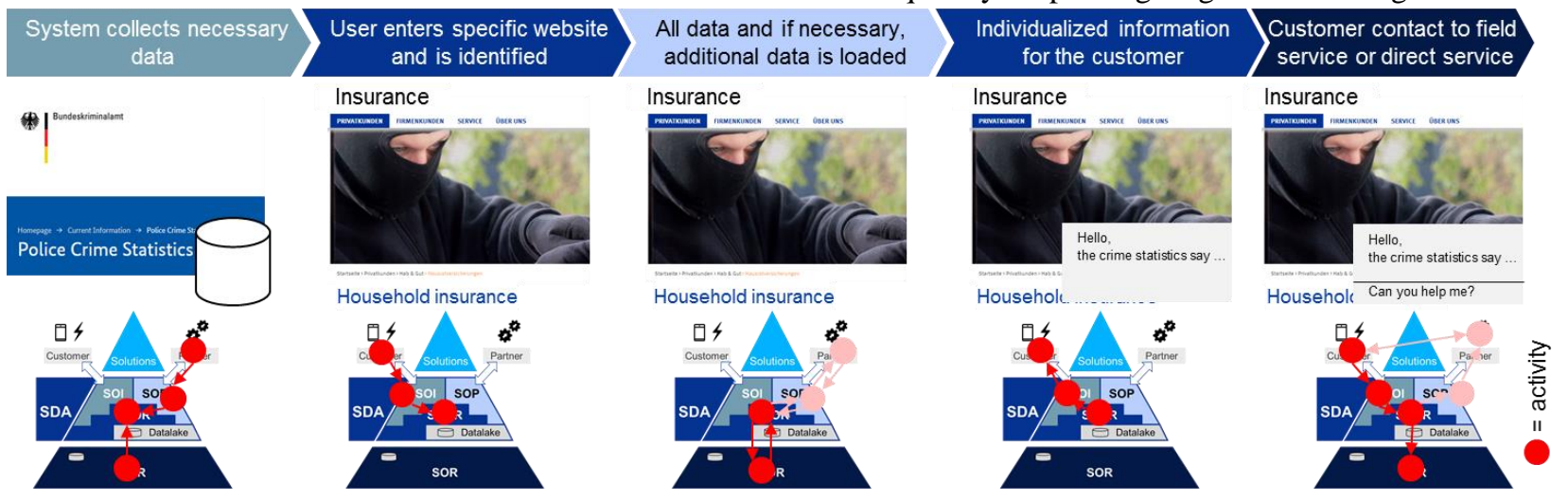

Figure 4. Embedded case study 3 - individualized information on website 
three cases, the SOI is responsible for gathering information about the customer and his interaction. Moreover, the SOP helps to integrate liquefied resources of partners.

The resource integration is the third important aspect of a service platform. In the cases studies, the service platform (SOI, SOP, SOOR) act as an integration platform for resources of different actors with the target to conduct cooperative value creation and to increase resource density (forth metatheoretical foundations). Hence, resource density is achieved by the data lake.

In addition to the confirmation of the metatheoretical foundations, the case studies show an important differentiation in the resources integration on service platforms. Considering literature, resource integration plays a central role in value creation [14, $32,33]$. The provision of service is an interactive process, in which all actors integrate their resources [14]. This characteristic is also observable in our case study when a service is provided to the customer.

However, as we observed, even more than just integrating resources for value creation, a service platform act as collecting point for integrated resources. In particular, the service platform integrates resources from other partners before value creation. For example, in case study three, crime statistics are loaded initially to the service platform (by the SOP) and applied if needed. In this case, we understand resource integration, not as part of a cocreation process; rather, we understand resources integration as the provision of resources to the service platform.

Thus, we observed that service platforms could integrate resources from other actors and apply them if necessary. Considering service research, this observation is also reflected by service-logic. Within service-logic, value creation is differentiated between value facilitation, value cocreation, and sole value creation [34, 35]. Within the value facilitation, the provider applies the service platform to develop a value proposition. If the customer is interested in the value proposition, the actual value cocreation begins. In contrast to $[34,35]$, a sole value creation of the customer does not exist, because the service platform is a crucial part of the value creation.

The possibility to apply resources independently from its integration leads to the need for resource management capabilities. A service platform stores resources and enables real-time access to them. By this, a dynamic configuration of resources is possible that enables the realization of innovative, previously unknown value propositions. To achieve this target, the service platform facilitates the management and adaption of resources. This management activity is also known as resource orchestration.
In particular, we understand resource orchestration as an overarching capability that encompasses the management and transformation of resources to apply and enable new service systems configurations. Resource orchestration contains capabilities that help to reorganize resources, to create service innovations, integrate complementary resources, and adapt roles, resources, and ownership in the service system [36, 37]. Moreover, orchestration also includes capabilities to modularize and compose resource configurations [4]. According to Sirmon et al. [38], resource orchestration comprises activities from resource management and asset orchestration. Thereby, activities encompass structuring, bundling, leveraging, search and selection, and configuration and deployment of resources.

From this point of view, the aim of the resource orchestration is not only to integrate resources but also to make them useable for cocreation. In this way, individual resource configurations can be created that allow specific value propositions.

An extraordinary case for operationalizing resource orchestration is super-individualization or mass customization. Mass customization can only be realized effectively if resources are available at the right time in the right place on the service platform. This means for a company that resources must be mobilized, integrated, and stored on the service platform before the value creation process. As soon as a specific customer request is submitted, the company must orchestrate all necessary resources and by this, deliver a customer-specific solution. In case of our insurance company, the insurer offers services through the SOI and thus, on the website and other mobile applications. Customers access the communication channels and use these services. At this moment, the service platform has to contain all necessary resources for service provision. Once a customer expresses a particular request, adequate resources are collected and formed into a customer-specific value proposition.

In the resource orchestration, there are manifold challenges. Mainly, they are triggered by a large number of available resources and their different origins. Because of this, resources can oppose, contradict, or neutralize each other. This means for the implementation of valuable solutions that available resources need a purposeful orchestration.

Through resource orchestration, individualizations can be made which correspond to the respective customer requirements. As an integration system for the resources, service platforms can thus be understood as a space or nexus between customer requirements and resources to align the value proposition to specific customer needs. Thereby, a company can create 
customer-centric services, which results in a higher customer value.

Table 1: Role of digital platforms in resource management

\begin{tabular}{|l|l|}
\hline $\begin{array}{l}\text { Theoretical } \\
\text { constructs }\end{array}$ & $\begin{array}{l}\text { Role of the digital platform (involved } \\
\text { parts of the SDA) }\end{array}$ \\
\hline $\begin{array}{l}\text { actor-to- } \\
\text { actor } \\
\text { networks }\end{array}$ & $\begin{array}{l}\text { - Integrating different customers and } \\
\text { partners to cooperative value creation } \\
\text { (SOI; SOP) }\end{array}$ \\
\hline $\begin{array}{l}\text { resource } \\
\text { liquefaction }\end{array}$ & $\begin{array}{l}\text { - Using digital technologies to gather } \\
\text { additional data from customers' (SOI) } \\
\text { - Applying complementary resources } \\
\text { from partners (SOP) }\end{array}$ \\
\hline $\begin{array}{l}\text { resource } \\
\text { integration }\end{array}$ & $\begin{array}{l}\text { - Integrating resources (SOI; SOP; } \\
\text { SOOR) for cooperative value creation } \\
\text { - Integrating resources (SOI; SOP; } \\
\text { SOOR) to a comprehensive platform }\end{array}$ \\
\hline $\begin{array}{l}\text { resource } \\
\text { density }\end{array}$ & $\begin{array}{l}\text { - Collecting and storing resources } \\
\text { (Data lake) }\end{array}$ \\
\hline $\begin{array}{l}\text { resource } \\
\text { orchestration }\end{array}$ & $\begin{array}{l}\text { - Management of integrated resources } \\
\text { to facilitate cocreation and service } \\
\text { innovation (whole service platform) }\end{array}$ \\
\hline
\end{tabular}

\subsection{Service innovation on service platforms}

Service innovation as the development of innovative service systems plays an important role for resource orchestration. According to S-D Logic, service innovations are enabled by resource density, as well as easy access to resources [4]. Both lead to dynamic and changeable resource combinations. Resource orchestration facilitates the management of resources and thus, helps to apply resources for customer-centric solutions.

Considering the role of the implemented digital platform, it was a mandatory basis for the implementation of new services. By facilitating resource liquefaction, integration, and orchestration, the platform enabled the insurer to search for and create new customer services, like in our use cases.

In our case, the major basis for the realized service innovations is the comprehensive knowledge about the customers. This knowledge is one of the main advantages of our company in comparison to digital attackers. To process this knowledge, the service platform transforms the largely static resources from the SOR into dynamically applicable resources. This makes resources accessible for the application in realtime value creation processes. Additionally, external partners are connected by the SOP and complementary resources integrated.

To enable innovative service systems, a structured development of the service system is necessary. In the development our cases, we were able to observe three different approaches. Firstly, an extension of the resource density. By adding further resources to the service platform, new resource combinations emerge that allow offering new value propositions [4]. Also, capabilities like artificial intelligence or machine learning are applied that allow searching for patterns in the resources. Secondly, a search for relevant value propositions based on the customer behavior. Here, the service platform uses direct interactions with the customer to enable the search for new services. In these interactions, the insurer collects inputs of the customer and data on his behavior. The collected data is the starting point for the search for a possible value proposition. After deriving requirements, the service platform facilitates the identification and integration of relevant resources. Lastly, the provision of new capabilities to process resources. These capabilities improve resource integration and orchestration and thus, enable the development of new service systems.

In the process from unstructured resources to a new service system, we can distinguish between three stages, how service innovation is facilitated by the platform (see Table 2). In the beginning, there are diverse unstructured resources on the platform. All resources are integrated from different systems and, optimally, the number of resources is permanently rising. The main target of this step is to exploit a complex network of different actors and to achieve a high resource density. Within this step, the service platform act as an enabler for resource exchange by mobilizing and liquefying resources. After that, resources are orchestrated on the platform. For this, the service platform offers different management capabilities that allow structuring, aggregate, and process resources. At this moment, relevant value propositions and resources for value creation are identified. Lastly, configured resource bundles are defined. In addition to that, the service platform allows implementing and resource configurations for service systems.

\section{Conclusion and outlook}

This paper reflects the role and purpose of service platforms in facilitating service systems. For this, we conduct a longitudinal single-case study that comprises three case studies as units of analysis. In the case study, we were able to accompany a German insurance company through a strategic process as well as the execution of the digital strategy. Within this process, the company developed reusable resource bundles for innovative service systems as well as value propositions that rely on a realized service platform. Based on the transformation process, we were able to gain a comprehensive perspective on the development 
Table 2: Managing resources with service platforms: objectives and mechanism

\begin{tabular}{|l|l|l|l|}
\hline $\begin{array}{l}\text { Resource } \\
\text { characteristics }\end{array}$ & $\begin{array}{l}\text { Unstructured; chaotic; } \\
\text { voluminously }\end{array}$ & $\begin{array}{l}\text { Processed; aggregated; } \\
\text { structured }\end{array}$ & Bundled; connected \\
\hline Objective & Integrated resources & Orchestrated resources & Configured resources \\
\hline $\begin{array}{l}\text { Performed } \\
\text { activity }\end{array}$ & $\begin{array}{l}\text { Integration of resources } \\
\text { through technical } \\
\text { service systems }\end{array}$ & $\begin{array}{l}\text { Orchestration of resources; } \\
\text { application of capabilities }\end{array}$ & $\begin{array}{l}\text { Service provision; Integration of } \\
\text { real-time resources and } \\
\text { complementary service }\end{array}$ \\
\hline $\begin{array}{l}\text { Responsible } \\
\text { service system }\end{array}$ & SOI; SOP; SOOR & Whole service platform & SOI; SOP \\
\hline
\end{tabular}

and use of service systems. As result of our research, resource orchestration as a management capability of service platforms is introduced and discussed. Moreover, the role of service platforms and resource orchestration in the development of innovative service systems is discussed.

Considering the results of our research, service platforms and service systems are pivotal concepts to implement digital business models and to achieve required business agility. The most important functions of a service platform comprise the integration and orchestration of resources. As research on S-D logic already stated, all actors are resource integrators [14, 39]. As interaction point between different actors, service platforms facilitate resource integration on a common base. Moreover, by exploiting digital technologies, a service platform enables extensive resource liquefaction. By this, a company can reach a higher resource density. However, the company must handle the resource density on the service platform and exploit the opportunities. For this, resource orchestration comes into play. Resource orchestration encompasses the management and transformation of resources to enable new service system configurations. Hence, the orchestration comprises all activities that are necessary to handle the resources on the service platform. This is of importance because a service platform can contain a huge amount of unstructured and perhaps meaningless resources. Only through among other things structuring, bundling, leveraging, and search and selection, resources get meaningful and enable offering a defined value proposition.

Besides of resource orchestration, also the role of the platform in service innovation is reflected. Here, the service platform aims at improving the ability to apply resources and thus, is focusing on service and organizational development. Implementing a service platform facilitates this process by enabling resource liquefaction, resource integration, and resource orchestration and applying these capabilities to design new service system configurations.
The results add to service research by discussing the role of service platforms in facilitating service systems. We have focused on resource management capabilities that help to achieve required resource density to develop unique value propositions, to cocreate value with customers, and to differentiate offerings through service innovation by embracing and incorporating digital technologies. Furthermore, this research adds to research on digital transformation by discussing the development of necessary resource management capabilities.

Even if our longitudinal case study is providing rich insights into a digital transformation process, the single company is a limitation of this paper. However, existing research on service systems and service innovations seems to support our findings.

The driving forces of digital transformation and service systems are worth investigating in future research. Moreover, future research could focus on the importance of service platforms in the development and operation of agile organizations.

\section{References}

[1] H. Demirkan, J.C. Spohrer, and J.J. Welser: 'Digital Innovation and Strategic Transformation', IT Professional, 2016, 18, (6), pp. 14-18

[2] J.W. Ross, I. Sebastian, C. Beath, M. Mocker, K. Moloney, and N. Fonstad: 'Designing and Executing Digital Strategies'. Proc. Thirty Seventh International Conference on Information Systems, Dublin2016

[3] A. Smedlund: 'Value Cocreation in Service Platform Business Models', Service Science, 2012, 4, (1), pp. 79-88

[4] R.F. Lusch, and S. Nambisan: 'Service Innovation: A Service-Dominant Logic Perspective', Mis Quarterly, 2015, 39, (1), pp. 155-175

[5] C. Petrie, A. Hochstein, and M. Genesereth: 'Semantics for Smart Services', in H. Demirkan, J.C. Spohrer, and V. Krishna (Eds.): 'The Science of Service Systems' (Springer US, 2011), pp. 91-105

[6] H. Demirkan, and D. Delen: 'Leveraging the capabilities of service-oriented decision support systems: Putting 
analytics and big data in cloud', Decision Support Systems, 2013, 55, (1), pp. 412-421

[7] H. Demirkan, C. Bess, J. Spohrer, A. Rayes, D. Allen, and Y. Moghaddam: 'Innovations with smart service systems: analytics, big data, cognitive assistance, and the internet of everything', Communications of the association for Information Systems, 2015, 37, (1), pp. 35

[8] M. Warg, and S. Rennebach: 'Service-orientierte Geschäftsmodelle und ihr Nutzen für Nachfrager und Anbieter', in T. Böhmann, P. Weiß, and M. Warg (Eds.): 'Service-orientierte Geschäftsmodelle - Erfolgreich umsetzen' (Springer Gabler, 2013)

[9] T. Clauss, and S.M. Laudien: 'Service-dominant Logic and Business Model Concepts: Fostering a Shotgun Wedding'. Proc. Naples Forum on Service 2013, Naples2013 pp. 18-21

[10] S.L. Vargo, and R.F. Lusch: 'Institutions and axioms: an extension and update of service-dominant logic', J. of the Academy of Marketing Science, 2016, 44, (1), pp. 5-23

[11] R.F. Lusch, S.L. Vargo, and G. Wessels: 'Toward a conceptual foundation for service science: Contributions from service-dominant logic', IBM systems journal, 2008, 47, (1), pp. 5-14

[12] C. Peters, P. Maglio, R. Badinelli, R.R. Harmon, R. Maull, J.C. Spohrer, T. Tuunanen, S.L. Vargo, J.J. Welser, and H. Demirkan: 'Emerging Digital Frontiers for Service Innovation', Comm. of the A. for Inf. Sys., 2016, 39, (1)

[13] S.L. Vargo, and R.F. Lusch: 'Service-dominant logic: continuing the evolution', Journal of the Academy of Marketing Science, 2008, 36, (1), pp. 1-10

[14] S.L. Vargo, and R.F. Lusch: 'Service-Dominant Logic Premises, Perspectives, Possibilities' (Cambridge University Press, 2014. 2014)

[15] S.L. Vargo, and R.F. Lusch: 'Evolving to a New Dominant Logic for Marketing', Journal of Marketing, 2004, 68, (January), pp. 1-17

[16] B. Edvardsson, B. Tronvoll, and T. Gruber: 'Expanding understanding of service exchange and value co-creation: a social construction approach', Journal of the Academy of Marketing Science, 2010, 39, (2), pp. 327-339

[17] J.D. Chandler, and S.L. Vargo: 'Contextualization and value-in-context: How context frames exchange', Marketing Theory, 2011, 11, (1), pp. 35-35

[18] B. Edvardsson, A. Gustafsson, and I. Roos: 'Service portraits in service research: a critical review', Int. J. of Service Industry Management, 2005, 16, (1), pp. 107-121

[19] J. Spohrer, and P.P. Maglio: 'Service science: Toward a smarter planet', in W. Karwowski, and G. Salvendy (Eds.): 'Introduction to service engineering' (John Wiley \& Sons, Inc., 2010), pp. 3-30

[20] J.C. Spohrer, and P.P. Maglio: 'Toward a Science of Service Systems', in P.P. Maglio, C.A Kieliszewski, and J.C. Spohrer (Eds.): 'Book Toward a Science of Service Systems' (Springer, 2010, edn.), pp. 157-194

[21] P.P. Maglio, S. Srinivasan, J.T. Kreulen, and J. Spohrer: 'Service systems, service scientists, SSME, and innovation', Comm. of the ACM, 2006, 49, (7), pp. 81-85
[22] J. Spohrer, P. Maglio, J. Bailey, and D. Gruhl: 'Steps toward a science of service systems', Computer, 2007, 40, (1), pp. 71-77

[23] J. Spohrer, and S.K. Kwan: 'Service science, management, engineering, and design (SSMED): an emerging discipline - outline and references', International J. of Information Sys. in the Service Sector, 2009, 1, (3)

[24] T. Böhmann, J.M. Leimeister, and K. Möslein: 'Service Systems Engineering', Business \& Information Systems Engineering, 2014, 6, (2), pp. 73-79

[25] P.P. Maglio, S.L. Vargo, N. Caswell, and J. Spohrer: 'The service system is the basic abstraction of service science', Information Systems and e-Business Management, 2009, 7, (4), pp. 395-406

[26] S. Miller: 'Social Institutions' (Metaphysics Research Lab, Stanford University, 2014, Winter 2014)

[27] M. Warg, P. Weiß, and R. Engel: 'Service Dominant Architecture' (FH Wedel, Univ. of Applied Science, 2015)

[28] M. Warg, and R. Engel: 'Service-Dominierte Architektur (SDA): Kernkomponente digitaler Transformation', Zeitschrift für Versicherungswesen, 2016, 2016, (12), pp. 391-395

[29] R.F. Lusch, S.L. Vargo, and M. Tanniru: 'Service, value networks and learning', Journal of the Academy of Marketing Science, 2010, 38, (1), pp. 19-31

[30] R.K. Yin: 'Case study research: Design and methods' (Sage publications, 2014. 2014)

[31] E. Gummesson: 'Qualitative methods in management research' (Sage, 2000. 2000)

[32] C. Mele, T.R. Spena, and M. Colurcio: 'Co-creating value innovation through resource integration', Int. Journal of Quality and Service Sciences, 2010, 2, (1), pp. 60-78

[33] L.D. Peters, H. Löbler, R.J. Brodie, C.F. Breidbach, L.D. Hollebeek, S.D. Smith, D. Sörhammar, and R.J. Varey: 'Theorizing about resource integration through servicedominant logic', Marketing Theory, 2014, 14, (3), pp. 249268

[34] C. Grönroos, and A. Ravald: 'Marketing and the Logic of Service: Value Facilitation, Value Creation and Cocreation, and Their Marketing Implications' (Hanken School of Economics, 2009)

[35] C. Grönroos, and P. Voima: 'Critical service logic: making sense of value creation and co-creation', J. of the Academy of Marketing Science, 2013, 41, (2), pp. 133-150

[36] D. Kindström, and C. Kowalkowski: 'Service-driven Business Model Innovation - Organizing the Shift from a Product-based to a Service-centric Business Model', in N.J. Foss, and T. Saebi (Eds.): 'Business Model Innovation: The Organizational Dimension' (Oxford Univ. Press, 2015)

[37] D. Kindström, C. Kowalkowski, and E. Sandberg: 'Enabling service innovation: A dynamic capabilities approach', J. of Bus. Res., 2013, 66, (8), pp. 1063-1073

[38] D.G. Sirmon, M.A. Hitt, R.D. Ireland, and B.A. Gilbert: 'Resource Orchestration to Create Competitive Advantage', J. of Mgmnt., 2011, 37, (5), pp. 1390-1412

[39] S.L. Vargo, and R.F. Lusch: 'It's all B2B... and beyond: Toward a systems perspective of the market', Industrial Marketing Mgmnt., 2011, 40, (2), pp. 181-187 